\title{
SUSTAINABLE DEVELOPMENT OF URBAN SPACES IN BULGARIA: THEORETICAL ASPECTS
}

\author{
M. Georgieva* \\ Department of Socio-economic Geography, Faculty of Geology and Geography, Sofia, Bulgaria
}

\begin{abstract}
The idea of sustainable development of urban areas is a part of the global model for sustainable development which is from the 70s of XX century when The World Conference of Human Development in Stockholm was carried out. Even then the belief sets that is necessary to create and manage urban areas with constantly changing characteristics of the natural system, human resources and socio-economic environment. The purpose of this report is to present the basic theoretical aspects related to the characteristics of urban areas in Bulgaria and their sustainable development in the context of European regional policy. Considering the trends in the processes of urbanization and complex challenges that face urban areas in Bulgaria, it is necessary to use some methods related to systematic and structural analysis as well as analysis of spatial connections and explore legal regulations. The survey results show the key role of cities in achieving an overall synergetic effect of policies on regional and urban development. In conclusion, it is made an attempt to prove that the proper management of urban areas in Bulgaria is a driving force with vital importance for sustainable development throughout.
\end{abstract}

Key words: urban areas, integrated approach, urban development, synergetic effect

\section{INTRODUCTION}

The idea of sustainable development stems from the World Conference of Human Development, held in 1972 in Stockholm, which focuses on the relationship between the natural and the socio-economic system. The persuasion of the conception is enough understandable and refers to the statement that human beings continuously assimilate and change the environment in which they live and permanently alter its characteristics. Considering the alarming evidence of environmental degradation appears a desire for a change and demand for ecological balance. Thus was born the idea of sustainable development as "a way to use the natural resources that aims to meet human needs while preserving the natural balance in the environment so that these needs can be met both at the current time and in the distant future" (1).

Understanding Sustainable Development brings together two major trends:

\footnotetext{
*Correspondence to: $M$. Georgieva, Department of Socio-economic Geography, Faculty of Geology and Geography, Sofia University, Sofia, Bulgaria, e-mail: maya_ms@abv.bg, Phone: +359886 135858
}

- $\quad$ Achieving economic development, ensuring high living standards;

- Protecting and improving the environment in the future.

Thus, the concept leads to the idea of integrating the constantly changing characteristics in urban areas, affecting public health, public works, transport and natural system, the relationship between urban and non-urban areas or between the city and its surroundings.

The report of the World Commission on Environment and Development of the United Nations - "Our Common Future" from 1987 develops the ideas of sustainable development, the role of cities and the impact of urbanization on the environment, i.e. "boosts the integration of environmental with the political agenda" (2). This document marks the beginning of the idea for sustainable development and for the endless disputes about its nature.

The aim of the study is to reveal and analyze some of the basic theoretical aspects of sustainable development of urban areas in Bulgaria, taking into account the combined effects of economic, social, cultural and 
environmental factors and policies in the field of integrated urban development.

\section{Tasks:}

- Clarification of theoretical and methodological issues relating to urban areas in Bulgaria - nature and development, clarification of basic concepts.

- Investigation of sustainable urban development in Bulgaria in the context of European regional policy.

\section{METHODS}

The interdisciplinary nature of the subjectmatter creates some difficulties in determining the overall methodology. However in the present study attempts to apply geographic systematic and structural analysis and analysis of spatial relationships between urban and nonurban areas in Bulgaria. For a better understanding of the subject, among these methods are considered and some European documents for integrated spatial planning. Essential passage in the report is given to the evaluation and analysis of integrated plans for urban regeneration and development in Bulgaria as well as methodological guidance on its design and application.

\section{RESULTS AND DISCUSSIONS}

After the conferences of the 70s and 80s of the last century society unites around the idea of sustainable development, realizing its responsibility not only for future generations but also for its existence. There are different interpretations of the term "sustainable development", which carry a similar sense and sound almost equally:

- $\quad$ "Sustainable development is a process of a change in which resource use, guide investments, the orientation of technological development and institutional changes are in total harmony and enhance both current and future potential to meet human needs and aspirations" (2).

- $\quad$ "Any society that sets itself the task of sustainable development needs to develop economically and socially in a way that minimizes those activities whose costs are borne by future generations, and where these activities are inevitable - to provide compensation future generations for these costs" (3).

- $\quad$ Sustainable development is a process of joint evolution of the interacting systems in a common environment in which each system follows its own path of self-organization to meet the challenges of their particular environment" (4).
In the messages of global forums and declarations of international organizations to realize the goals of sustainable development is recognizing a tendency to focus on planning and development of sustainable and vibrant cities, which must ensure "long-term human health and protection of ecosystems, to distinguish the needs of current and future generations of their desires and to get rid of the idea of "ownership", which is difficult to apply in respect of rights" (5).

To reveal peculiarities in the sustainable development of urban areas, it is appropriate first to clarify the nature of certain fundamental concepts.

The term "space" has an interdisciplinary status and corresponds with geography, sociology, economics and all spatial sciences. It is closely related to the concept of "region", which is essential for regional science and geography. It can be assumed that each region is space, but not every space is a region. The last supposed a higher degree of organization (6). There are a wide variety of concepts of space that develop over time and have large varieties.

Urbanized area often associated with urban territory. This is a territory whose physical forms are part of the city and is characterized by a considerable built-up areas, high population density and areas of work, developed transport and other infrastructure. Urbanized area also includes undeveloped green areas used for recreational purposes.

Furthermore, it is appropriate to clarify the essence of sustainable spatial development. It is the main goal in the Guiding Principles for Sustainable Spatial Development of the European continent. It is assumed that the steadiness is associated with long-term approaches and the benefits provided by spatial development policies are long term in nature and should not conflict with other public policies and sectoral activities. The guiding principles of the European Spatial Development Policy identify four elements of territorial stability and the economic, social and environmental added and cultural sustainability. In the center of sustainable development of urban areas stands a broader sustainability agenda, bringing together the main priorities - protecting environmental quality, social equity, cohesion and economic prosperity. The comprehensive and integrated approach rejects the principle of separation of objectives related to different aspects of the urban environment, and thus facilitates the 
establishment of balance in all levels of planning - national, regional and local.

Sustainable urban management is based on the principles of sustainable development, thanks to which it solves specific and key problems of urban areas, i.e. it combines measures of physical urban renewal with measures to improve education, economic development, social and environmental protection. In this line of thinking should not be missed to give priority to the importance of an integrated policy approach to urban planning and development because of improving the sustainable urban development and enhance the sustainability of cities. The integration of the constituent elements in urban areas puts the necessary conditions for their effective and sustainable use and has a real impact on national policies with spatial and institutional interactions.

Leipzig Charter on Sustainable European Cities (2007) synthesizes the general principles and strategies for sustainable urban development which puts the basis of the common strategic framework and defines national policies in this area (7). The document is a peculiar step towards the introduction of an independent European policy for urban development and focuses on the areas in physical, social and economic decline. Charter has a decisive role of integrated urban planning, the principles of which are binding on all policies, programs, plans and projects for urban development. The document establishes the possibility of achieving a high standard of urban environment by approving a synergy from all cultural, economic, technological, social and environmental aspects that influence quality and process of planning and management.

Toledo Declaration (2010) focuses on current challenges and opportunities for cities to achieve the objectives of the Europe 2020 Strategy - namely smart, sustainable and inclusive urban development. It exceeds the framework of the policy statement and reference for integrated urban renewal and is a kind of guide for the development of integrated plans. The document describes in detail all aspects of the integrated approach, coordination of policies at different hierarchical levels and sectors and the possible instruments (8).

Provisions and recommendations of all documents are generally organized in one direction and pursue a clearly stated goal consolidating the actions of a single urban agenda as a joint working program of the EU. The basic idea is that the development of urban areas, the capacity of their residents and the quality of social capital depends on the success of all the other common policies and programs of the EU. This logically leads to decisions to finance urban renewal projects from European funds for areas that have prepared integrated development plans.

The characteristics of the integrated urban development include several important components. The first of these relates to the management, which is performed from bottom to top rather than top to bottom. The second is the orientation of the objectives, strategies, measures and projects in the context of the regional approach and the overall urban approach. The third important component refers to the ability to adapt sectoral policies to cover potential areas or adjacent areas, especially those with neglected or secondary development.

Bulgaria observes closely the theme of sustainable urban development. The integrated upgrade after incorporation the country in EU has an important place in the National Strategic Reference Framework for the period 2007-2013. Operational Program "Regional Development" is mainly linked to National Strategic Reference Framework Priority 4 Balanced Territorial Development. It is expected more than half of the resources of the funds to be for Priority Axis 1 of Operational Program "Regional Development" "Sustainable and smart development". In the current programming period (2014 - 2020) only cities with approved plans for integrated urban regeneration and development will be financed.

According to additional provisions of the Low of Regional Development (SG 50 / 30.05.2008) "Integrated Urban Development Plan" is a plan for economic and social development or reconstruction of the village a town or a part of it that is developed for the implementation of the operational program "Regional Development", as well as other operational programs that finance projects in cities" (9).

In the month of July 2010 the Ministry of Regional Development and Public Works published Methodological guidelines for the development and implementation of integrated urban regeneration and development (10), which gives explanations about the nature and content of integrated plans. Summary understanding of the concept is that integrated 
policies and plans integrate together projects, actions and investment in certain areas of influence in the cities that belong to a particular target group. Methodological guidelines require a synergistic effect from all actions and proposed projects. There is a difference between master plans and integrated development plans in its limits, scope, time horizon and content.

The scope of integrated development plans covers the urban area of towns in regulatory limits. Criticism of this requirement is to unequal treatment of the city and the municipality. However, this approach makes it possible to achieve a better synergetic effect without encouraging investment in infrastructure of newly warehouses, residential and resort areas on farmland, reinforcing trends for extensive development. In literature it is known as "urban sprawl". According to some studies the concentration of investments from different sources in the city center and related residential and industrial areas creates the overall effect of spatially bound projects. This should be a consistent policy of municipalities to exhaustion capacity of these spaces. The structure of integrated development plans includes activities that cover the tasks of analysis, strategic, financial, operational and communicational part of the plan, as well as the management, monitoring and overseeing the implementation of these plans.

It cannot fail to note that funding of projects is carried out mainly by European funds. Also, strategic goals and priorities should correspond with Community objectives of integrated urban development, namely:

- Intelligent growth through intelligent integration of resources, cooperation and partnership with the state, scientific and educational institutions, private businesses, invests in innovative designs and high-tech research, infrastructure and services.

- Sustainable growth through upgrading and rehabilitation of abandoned buildings and land, compaction of neighborhoods, improve environmental quality, protection and development of the green system, effective waste management, reducing the use of non-renewable resources and energy dependence.

- Inclusive growth by supporting equitable community development, creating an accessible environment, providing suitable jobs and choices in the labor market and etc.

- Integrated renovation on the basis of broad partnership by integrating the objectives for smart, sustainable and inclusive growth via spatial, temporal and thematic integration of different projects.

The most important operative part from the work of integrated plans starts with evaluation, discussion and approval of the zones of influence. It includes a detailed study of problematic urban areas, demographic and economic statistic information, assessment of the state of transport and technical infrastructure, the environment and etc. Methodological guidelines provide a definition of the areas of impact. These are separate urban areas with a certain basic function with similar characteristics and condition of the physical environment, social and ethnic structure of the population as well as the nature and structure of the main funds.

In the first generation integrated development plans in Bulgaria, that are prepared in programming period 2007 - 2013, the realization of the projects is expected to be during the current period (2014-2020). There are three types defined as areas of impact:

The first type is "Areas with a prevailing social character". These are areas, dominated by multi-family residential buildings, industrially built more than 20 years, in which there are worse built and outdated technical infrastructure, unsupported green areas, gardens and public spaces, high long-term unemployment, poverty, social and ethnic problems, high levels of crime, poor condition of buildings and low energy efficiency.

The second type is "Areas with a potential for economic development". These are areas where predominantly are developing production and business activities, there are signs of urban decay - unsupported and /or abandoned buildings, unfinished or outdated transport or technical infrastructure, high energy intensity of buildings and facilities, poor condition of public spaces, parking lots, gardens and more. It is also important to there are vacant grounds with clear ownership, no restrictions for future development and an availability of investment interest.

The third type is "Areas of public functions with high public importance". These are community centers with a concentration of public and administrative buildings, important public spaces and stored real cultural values.

Methodological guidelines put a number of basic and additional measures for all zones of influence. In part of integrated development plans the zones of influence are separated from each other or connected by narrow linear links. 
It hampers integrated impact and achievement of synergic effect as well as the complete working of urban spaces.

\section{CONCLUSION}

The study of theoretical aspects in the development of urban areas in Bulgaria sets a number of challenges to the idea of creating and preservation the stability in them. The dynamics of change in the development of territories and settlements requires extension of integrated planning field beyond bounders of sustainability. The main and most serious questions that are to be reviewed and discussed, related to the effective use of urban spaces, overcoming demographic problems and social disparities in the territories, ensuring cultural diversity and high quality urban environment. Preservation of balance and strengthening relationships of urban with nonurban areas is a precondition for establishment of modern sustainable models for urban development.

\section{REFERENCES}

1. Sandeva, V. \& Katerina Despot, Sustainable development of green areas in the town of Skopie, Republic of Makedonia, Management and Sustainable Development, 2012.
2. United Nations, Our Common Future, Report of the World Commission on Environment and Development, pp. 37 38, 1987.

3. Pearce, D. \& Jeremy J. Warford. World Without End - Economics, Environment and Sustainable Development. Ney York: Oxford Press, 1993.

4. Bossel, H., Indicators for Sustainable Development: Theory, Method, Applications, Winnipeg, Manitoba, Canada: International Institute for Sustainable Development, 1999.

5. Wheeler, St., Planning for Sustainability: Creating Livable, Equitable and Ecological Communities, Routledge, 2004.

6. Stoyanov, P., German "space organization", Sofia, 2009.

7. Kovachev, A., V. Troeva and etc., Integrated spatial and urban planning. In: The Town, Varna, pp. 211 - 255, 2013.

8. http://www.eukn.org/News/June/Ministers_ of_Housing_and_Urban_Development_app rove_the_Toledo_Declaration

9. The Law of Regional Development (SG 50 / 30.05.2008)

10. Methodological guidelines for the development and implementation of integrated urban regeneration and development - new version (19.05.2015) 